\title{
Clinical and morphological evaluation of gold micro shunt after unsuccessful surgical treatment of patients with primary open-angle glaucoma
}

${ }^{1}$ Ophthalmology Department, Military Institute of Medicine, Warsaw, Poland

${ }^{2}$ Pathology Department, Military Institute of Medicine, Warsaw, Poland

Correspondence: M Rękas, Ophthalmology Department, Military Institute of Medicine, Szaseŕow 128, 63 Karol Szymanowski St., Marki 05-270, Poland.

Tel: + 48227714349;

Fax: + 48226816575;

E-mails: rekaspl@gmail.com or mrekas@wim.mil.pl

Received: 29 August 2012 Accepted in revised form: 13 June 2013 Published online: 19 July 2013

This paper was presented (oral presentation) during the 6th International Congress on Glaucoma Surgery, Glasgow, Scotland, 13-15 September 2012.

\begin{abstract}
Purpose To report the clinicopathologic features in a series of patients after ineffective glaucoma surgery with gold micro shunts (GMS) 2 years after the procedure. Methods This was an interventional case series study including two cases of GMS and two of GMS + removal. Each specimen was sectioned into three portions: proximal, middle, and distal, and embedded into paraffin blocks, cut into $3 \mu \mathrm{m}$ sections and stained with hematoxylin and eosin and Masson's trichrome. In the case of inflammatory infiltrations a reaction with an LCA (CD45) monoclonal antibody was performed.
\end{abstract}

Results Mean IOP before GMS removal was $28.8 \pm 4.3 \mathrm{~mm} \mathrm{Hg}$, and the patients were administered $2.3 \pm 0.5$ anti-glaucoma drugs. The progression of changes in the visual field was observed in all cases. In three cases different grade intensification of corneal decompression was observed. Colonization of the connective tissue was found in the channels and around the microimplant in all cases. In two cases infiltration was detected from giant polynuclear and mononuclear cells.

Conclusions Connective tissue colonization was the cause of GMS obstruction. This can be a non-inflammatory process, but it may also result from chronic inflammation occurring in the suprachoroidal space. Eye (2013) 27, 1214-1217; doi:10.1038/eye.2013.154; published online 19 July 2013
M Rękas', B Pawlik', B Grala² and W Kozłowski²

Keywords: suprachoroidal space;

unconventional outflow pathway; glaucoma surgery

Introduction

Hydrostatic pressure difference between the anterior chamber and the suprachoroidal space is the basis for surgical use of the unconventional outflow pathway. ${ }^{1}$ Implants enhancing the unconventional outflow pathway have already undergone specific evolution through GMS (SOLX Inc., Occulogix, Waltham, MA, USA) used via an ab externo approach to CyPassMicro-Stent (Transcend Medical) the implantation of which is performed from the anterior chamber to the suprachoroidal space. ${ }^{2,3}$ However, it seems that the physiology of suprachoroidal space has not been well recognized yet as regards the possibility of IOP regulation and the reaction to the presence of a foreign body in the long-term follow-up.

\section{Case reports}

There were four patients aged $70.2 \pm 15.5$ years with POAG. Mean IOP before GMS implantation was $22.5 \pm 3.5 \mathrm{~mm} \mathrm{Hg}$, and the patients used $2.5 \pm 0.6$ (median: $\mathrm{Me}-2.5$ ) medications. The mean IOP before GMS removal was $28.8 \pm 4.3 \mathrm{~mm} \mathrm{Hg}(P=0.002)$, and the patients used $2.3 \pm 0.5(\mathrm{Me}-2.0)$ medications $(P=0.361)$. The mean time for the implant removal was $29.8 \pm 8.3$ months. 


\section{Case 1}

A 90-year-old man with GMS removed from the right eye 29 months after implantation. IOP was $25.0 \mathrm{~mm} \mathrm{Hg}$ (Ganfort), and progression in the visual field was observed $(\mathrm{MD}=-17.91)$. The central corneal thickness (CCT) increased from 480 to $568 \mu \mathrm{m}$ and the corneal decompensation was detected despite the lack of GMS contact with the endothelium (OCT Visante). In the middle portion of GMS the presence of collagen-rich connective capsule-like reaction about $100-\mu \mathrm{m}$ thick was found (Figure 1). The presence of cell-rich collagen-poor connective tissue was also found between the plates. There were also observed chronic inflammatory infiltration cells, polynuclear giant cells, and small blood vessels (Figure 2a).

\section{Case 2}

In the case of a 69-year-old woman GMS + was removed from the left eye 21 months after surgery. Before removal, IOP was $24.0 \mathrm{~mm} \mathrm{Hg}$ (Xalacom). Progression in the visual field $(\mathrm{MD}=-8.55)$ and corneal decompensation were observed. CCT increased from 534 to $676 \mu \mathrm{m}$ despite the lack of GMS contact with the endothelium. In the middle portion of GMS the presence of collagen-rich connective capsule-like reaction was detected, but the capsule was thin (about $50 \mu \mathrm{m}$ ). In case no. 2 the presence of cell-rich collagen-poor connective tissue was found between the plates.
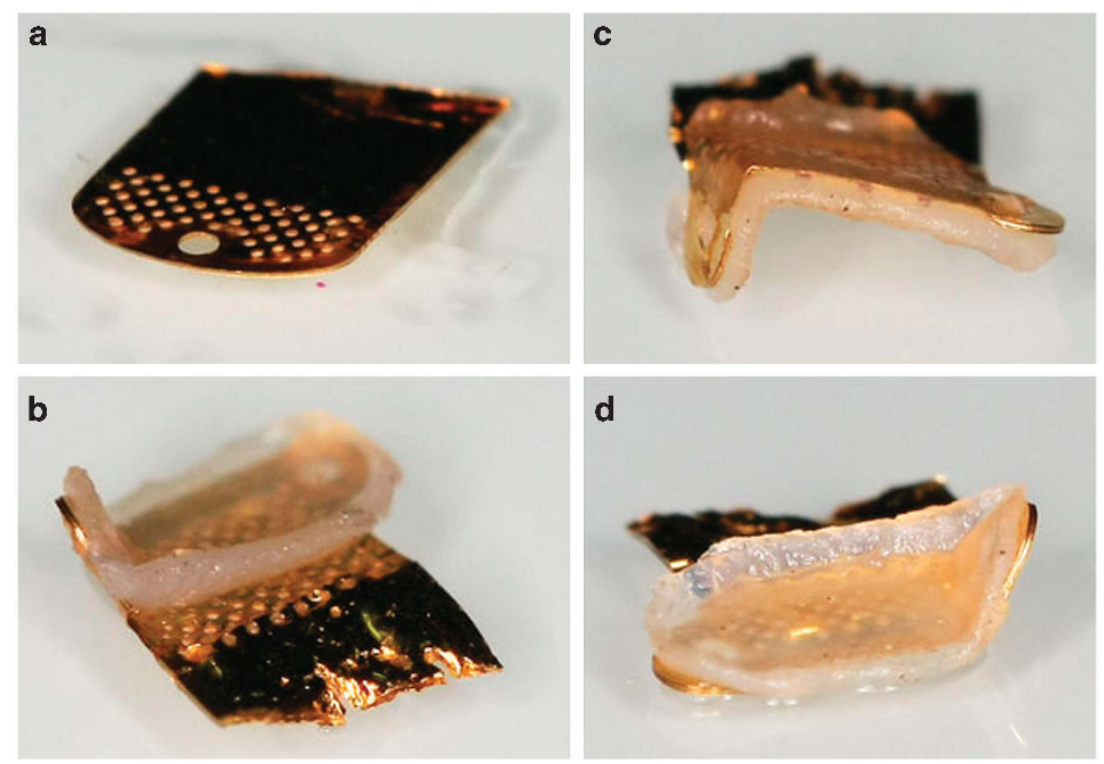

Figure 1 Macroscopic image of the removed microimplant (case 1). Colonization of the connective tissue around the microimplant. (a) Proximal portion; fragments of the connective tissue at the side of the sclera, $(b-d)$ distal portion: connective tissue (at the choroidal side) blocking the channels of the microimplant (Cannon EF $100 \mathrm{~mm} \mathrm{f/2.8} \mathrm{L} \mathrm{Macro} \mathrm{IS} \mathrm{USM).}$
Case 3

The cause of GMS removal from a right eye of a 70-yearold man was the decrease of endothelium from 2579 to 1685 cells $\mathrm{mm}^{-2}$ despite the lack of contact with GMS, and progression in the visual field was observed $(\mathrm{MD}=-3.49)$. IOP was $22.0 \mathrm{~mm} \mathrm{Hg}$ (Ganfort) 28 months after the surgery. In the middle and distal part the GMS was surrounded by collagen-rich connective tissue capsule. The proximal, middle and distal portion channels were partially filled with dense amorphous protein masses (Figure 2b).

\section{Case 4}

In a 52-year-old man, 41 months after primary surgery, GMS + was removed from the right eye because of the lack of IOP control despite of the maximal antiglaucoma therapy (Duotrav, Azopt). There were observed an increase of IOP to $41.0 \mathrm{~mm} \mathrm{Hg}$ and progression in the visual field $(\mathrm{MD}=-4.23)$. No contact of the implant with the endothelium was observed. Collagen-rich connective tissue in the implant channels and dispersed chronic inflammatory infiltrations both around and inside the implant were detected. Lymphocytic infiltration (LCA + ) was accompanied with clusters of numerous polynuclear giant cells (Figure $2 \mathrm{c}$ and $\mathrm{d}$ ).

\section{Discussion}

GMS is one of the most modern implants improving the unconventional pathway outflow. Despite encouraging

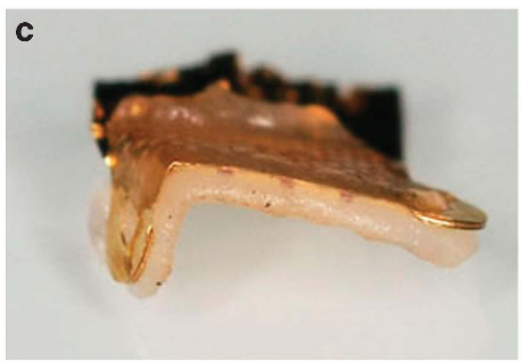



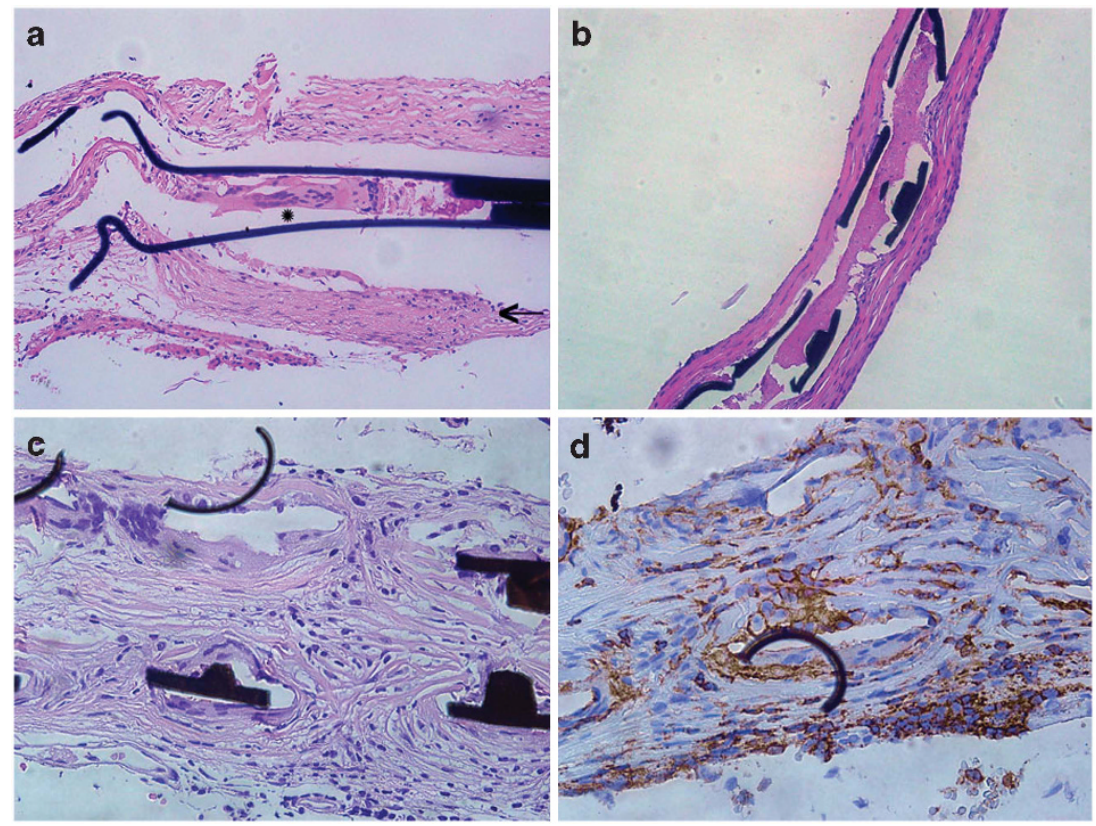

Figure 2 Microphotograph of the removed microimplant. (a) Case 1: in the middle portion the implant is surrounded by collagen-rich connective tissue capsule. A cluster of polynuclear giant cells present between the implant plates (asterisk). On the left side the giant cells combine with collagen-poor granulation tissue with numerous small blood vessels filling the remaining part of the microimplant channel. Below, within the sclera, is shown a visible focus of dispersed inflammatory infiltration (arrow) (H\&E $\times 200)$. (b) Case 3: amorphous thickened protein masses between microimplant plates $(H \& E \times 200)$. (c) Case 4: inflammatory infiltrations from lymphocytic cells between the GMS plates $(H \& E \times 400)$. (d) Case 4: the membrane expression of LCA (CD45) in the infiltration from mononuclear cells (immunohistochemical staining with a anti-LCA antibody $\times 400$ ).

initial clinical reports, in the medium-term follow-up the IOP reduction decreased, whereas the number of applied anti-glaucoma medications increased. ${ }^{4}$ It was suggested that the formation of a fibrotic capsule around the device was responsible for the failure of the GMS surgery. ${ }^{4-6}$ We found fibroblasts both around the microimplant and within GMS channels. Apart from connective tissue, amorphous masses were also found in the proximal portion of the microimplant. It cannot be excluded that due to nutritional disorders there came to the degeneration of collagenized connective tissue.

The presence of giant cells both around and inside the microimplant may point to the role of activated monocytes and macrophages in the pathomechanism of the development of GMS obstruction. Distinct inflammatory infiltrations from mononuclear cells were also observed in the specimens. Their occurrence proves specific immune response to the antigen presented by macrophages.

Summing up, it should be concluded that microimplant obstruction caused by the connective tissue proliferation is the cause of the failure of surgery with GMS. This process can be non-inflammatory, but it can also result from chronic inflammation in the suprachoroidal space.

\section{Summary}

\section{What was known before}

- To date, single studies have been published related to the use of GMS in the surgical treatment of glaucoma. Early observations presented encouraging results, whereas in medium-term follow-up the decrease of the efficacy of this type of the surgical treatment was observed. In one publication, there was presented a histological examination of removed GMS, which revealed that fibrosis outside and inside GMS channels was the main cause of the microimplant obstruction.

\section{What this study adds}

- In the present study, we have confirmed that fibrosis is the main cause of GMS microimplant obstruction and thus of clinical failure of the surgery in these cases. However, it is worth noticing that the applied different methodology of the histological examination enabled immunohistochemical diagnostics and better insight into cellular mechanisms of fibrosis being in progress. Thus, it seems that fibroblast proliferation can be a reaction to a foreign body, as well as it can be stimulated by chronic inflammatory process.

\section{Conflict of interest}

The authors declare no conflict of interest. 


\section{Acknowledgements}

We thank a professional translator who translated and corrected the English language.

\section{References}

1 Emi K, Pederson JE, Toris CB. Hydrostatic pressure of the suprachoroidal space. Invest Ophthalmol Vis Sci 1989; 30: 233-238.

2 Melamed S, Ben Simon GJ, Goldenfeld M, Simon G. Efficacy and safety of gold micro shunt implantation to supraciliary space in patients with glaucoma: a pilot study. Arch Ophthalmol 2009; 127: 264-269.

3 Saheb H, Ahmed II. Micro-invasive glaucoma surgery: current perspectives and future directions. Curr Opin Ophthalmol 2012; 23: 96-104.
4 Figus M, Lazzeri S, Fogagnolo P, Iester M, Martinelli P, Nardi M. Supraciliary shunt in refractory glaucoma. Br J Ophthalmol 2011; 95: 1537-1541.

5 Mastropasqua L, Agnifili L, Ciancaglini M, Nubile M, Carpineto P, Fasanella $\mathrm{V}$ et al. In vivo analysis of conjunctiva in gold micro shunt implantation for glaucoma. $\mathrm{Br} \mathrm{J}$ Ophthalmol 2010; 94: 1592-1596.

6 Agnifili L, Costagliola C, Figus M, Iezzi G, Piattelli A, Carpineto $\mathrm{P}$ et al. Histological findings of failed gold micro shunts in primary open-angle glaucoma. Graefes Arch Clin Exp Ophthalmol 2012; 250: 143-149.

(c) (i) (2) This work is licensed under a Creative Commons Attribution-NonCommercialShareAlike 3.0 Unported License. To view a copy of this license, visit http://creativecommons.org/licenses/by-nc$\mathrm{sa} / 3.0 /$ 